\title{
Medievalista
}

Online

$14 \mid 2013$

Número 14

\section{Maria Amélia Álvaro de Campos - Santa Justa de Coimbra na Idade Média: o espaço urbano, religioso e socio-económico}

Dissertação de Doutoramento em História da Idade Média, apresentada à Faculdade de Letras da Universidade de Coimbra, sob orientação da Professora Doutora Maria Helena da Cruz Coelho, 2 volumes (texto policopiado)

\section{Maria Leonor Botelho}

\section{CpenEdition}

\section{Edição electrónica}

URL: http://journals.openedition.org/medievalista/445

DOI: 10.4000/medievalista.445

ISSN: 1646-740X

\section{Editora}

Instituto de Estudos Medievais - FCSH-UNL

Refêrencia eletrónica

Maria Leonor Botelho, « Maria Amélia Álvaro de Campos - Santa Justa de Coimbra na Idade Média: o espaço urbano, religioso e socio-económico », Medievalista [Online], 14 | 2013, posto online no dia 03 fevereiro 2014, consultado o 22 setembro 2020. URL : http://journals.openedition.org/medievalista/ 445 ; DOI : https://doi.org/10.4000/medievalista.445

\section{(c) (†) 8}

Mediavalista está licenciado com uma Licença Creative Commons - Atribuição-NãoComercial 4.0 Internacional. 
Título: Recensão

CAMPOS, Maria Amélia Álvaro de - Santa Justa de Coimbra na Idade Média: o espaço urbano, religioso e socio-económico. Coimbra: 2012.

Dissertação de Doutoramento em História da Idade Média, apresentada à Faculdade de Letras da Universidade de Coimbra, sob orientação da Professora Doutora Maria Helena da Cruz Coelho, 2 volumes (texto policopiado).

Autor(es): Maria Leonor Botelho

Enquadramento Institucional: DCTP/FLUP, Porto, Portugal

Contacto: leonorbotelho@gmail.com

Fonte: Medievalista [Em linha]. №14, (Julho - Dezembro 2013). Dir. José Mattoso.

Lisboa: IEM.

Disponível em: http://www2.fcsh.unl.pt/iem/medievalista/

ISSN: 1646-740X

\section{Recensão}

CAMPOS, Maria Amélia Álvaro de - Santa Justa de Coimbra na Idade Média: o espaço urbano, religioso e socio-económico. Coimbra: 2012.

Dissertação de Doutoramento em História da Idade Média, apresentada à Faculdade de Letras da Universidade de Coimbra, sob orientação da Professora Doutora Maria Helena da Cruz Coelho, 2 volumes (texto policopiado).

\section{Maria Leonor Botelho}


Na Sala dos Capelos da Universidade de Coimbra, a 19 de Dezembro de 2012, foram realizadas as Provas Públicas que aprovaram por unanimidade com Distinção e Louvor a então candidata, Maria Amélia Álvaro Campos. O aturado estudo consagrado à colegiada de Santa Justa de Coimbra na Idade Média, centrou-se sobre a análise do espaço urbano no qual a colegiada e paróquia de Santa Justa se firmou e expandiu entre os séculos XI e XV, mas também não olvidou a análise dos seus espaços religiosos $e$ socio-económicos. A tese de Doutoramento que agora analisamos contou com a orientação da Professora Doutora Maria Helena da Cruz Coelho e com a Professoras Doutoras Hermínia Vasconcelos Vilar e Maria José Azevedo Santos como arguentes. O júri das provas foi ainda integrado pela Professora Doutora Maria Alegria Fernandes Marques, pela Professora Doutora Ana Maria Rodrigues e pelo Professor Doutor Saul António Gomes.

Em primeiro lugar gostaríamos de salientar a pertinência deste estudo nas suas mais diversas perspectivas. Como se sabe, Santa Justa de Coimbra foi um dos primeiros institutos eclesiásticos da cidade do Mondego, filiado, desde os inícios do século XII, tal como São Pedro de Rates (Póvoa de Varzim), no priorado de Sainte Marie de la Charitè-sur-Loire (França), ficando assim directamente ligado a uma das principais casas da Ordem de Cluny. Todavia, as constantes cheias do leito deste rio obrigaram, a determinada altura, ao abandono da igreja medieva (que se julga românica) e à edificação de uma nova, cuja primeira pedra foi lançada em 1710. O facto da autora se centrar sobre a história de uma colegiada, cujos testemunhos materiais da época em estudo são hoje praticamente desconhecidos, torna este trabalho bastante audaz.

Este aspecto foi, aliás, facilmente contornado por Maria Amélia Campos por ter procedido ao cotejo de um imenso fundo documental cujo aro cronológico se estende entre 1098 e 1451 . Na sua maioria de natureza económica, as informações cruzadas pela autora procedem de documentos escritos entre os séculos XII e XV. Partindo da mais antiga referência documental sobre a igreja de Santa Justa, a autora escolheu o priorado de João Afonso (1441-1451) como terminus. Tão ampla cronologia permitiu realizar abordagens múltiplas em torno desta colegiada, sede de uma das nove paróquias da cidade de Coimbra, como ainda construir um grande número de anexos que, compilados no segundo volume do estudo, nos dão a conhecer a colegiada através dos números e 
dos documentos propriamente ditos. O tratamento gráfico dado a esta informação, visível através de tabelas, gráficos e imagens é de louvar.

A par da transcrição de 24 documentos, a autora dá-nos 147 notícias biográficas. Atentemos a este aspecto que cremos fundamental. A História não se faz sem pessoas e, naturalmente, Santa Justa de Coimbra não se fez sem elas. A dimensão humana assume neste estudo contornos importantes, não só pela preocupação em se conhecer quem foram as figuras que fizeram desta colegiada urbana uma das mais ricas instituições eclesiásticas de Coimbra durante a Idade Média, como também pelo facto da autora procurar compreender a constituição da comunidade eclesiástica de Santa Justa a partir de 1175 , data em que reconhece, pela primeira vez, a existência de um cabido. Na entrada de Trezentos contava já a Colegiada com os seus próprios estatutos.

Simultaneamente, a autora procurou descrever a sociotopografia de Santa Justa. Partindo da metodologia apresentada por Conceição Falcão Ferreira para a Guimarães medieval $^{1}$, Maria Amélia Campos procurou caracterizar uma freguesia plural na ocupação dos seus habitantes laicos, inserindo-os no espaço que habitavam. $\mathrm{O}$ recurso a um método de abordagem de um micro-espaço urbano anteriormente experimentado mostra da parte da autora o conhecimento de estudos similares, como ainda o reconhecimento da sua potencialidade prática.

A dimensão urbana de Santa Justa é por demais evidente. Se primeiramente se identifica com os arrabaldes de Coimbra, o aturado estudo documental mostrou aqui que rapidamente a freguesia se expandiu territorialmente. O estudo da paróquia medieval conheceu em Carlos Alberto Ferreira de Almeida (1934-1996) uma primeira abordagem $^{2}$. Partindo de uma perspectiva antropológica, este autor procurou sobretudo integrar a paróquia românica na sua territorialidade, então maioritariamente de carácter

\footnotetext{
${ }^{1}$ FERREIRA, Maria da Conceição Falcão - Guimarães. Duas Vilas, um só Povo. Estudo de história urbana (1250-1389). Braga: CITCEM, 2010.

2 ALMEIDA, Carlos Alberto Ferreira de - "A Paróquia e o seu Território". In Cadernos do Noroeste. Sociedade, Espaço, Cultura. Braga: Universidade do Minho. Vol. I (Abril 1986), pp. 113-130; Idem "Território Paroquial de Entre-Douro-e-Minho. Sua Sacralização". In Nova Renascença. Porto: Associação Cultural "Nova Renascença". Vol. I, no 2 (1981), pp. 202-212.
} 
rural. Propomos agora a Maria Amélia Campos que, num estudo futuro, faça uma abordagem crítica e estabeleça um contraponto entre os conceitos, vivências e espaço da paróquia urbana e da paróquia rural no Portugal medievo ou, se assim o entender por questões metodológicas, no termo de Coimbra. Creio que esta abordagem facilmente teria sido integrada no estudo que agora abordamos mas também o sabemos que as opções metodológicas encetadas nem sempre nos permitem abarcar tudo, fazendo das Teses de Doutoramento levadas a Provas Públicas uma caixa de Pandora. Neste sentido, consideramos antes que estas não devem constituir em si uma investigação fechada, mas antes um processo que se abre a projetos futuros pelas pistas e bases que são criadas.

Maria Amélia Campos procura constantemente justificar as opções metodológicas seguidas, quer ao nível da construção dos anexos que apoiaram a argumentação, quer ainda ao longo desta última. Em termos bibliográficos foi opção da autora apenas arrolar os Estudos Citados (vol. 2, p. 317 e ss.), muito embora sejamos da opinião de que as suas leituras foram mais além dos mesmos. Metodologicamente defendemos a criação de bibliografias mais completas, embora acreditemos que tal facto não terá interferido na qualidade do estudo. Trata-se apenas de uma opção metodológica. Neste campo, gostaríamos ainda de salientar a variedade de Índices que compõem este estudo e que em muito facilitam a sua leitura integrada: Quadros (vol. 2, p. 354-355), Gráficos (355-361), Imagens (vol. 2, p. 361-362), Apêndice de Documentos (vol. 2, p. 362-368) e Notícias Biográficas dos Eclesiásticos de Santa Justa (vol. 2, p. 368).

Estruturando a sua argumentação em três partes distintas - I. A Igreja e a Freguesia de Santa Justa de Coimbra; II. A estrutura capitular e colegial da igreja de Santa Justa; III. O património imóvel da colegiada de Santa Justa -, a autora procurou desde logo organizar as abordagens temáticas a que se propôs desde início: o espaço urbano, religioso e sócio-económico. Aparentemente estanques entre si, a informação relativa a estes três espaços que identifica em Santa Justa foi sempre e constantemente articulada entre si. Assim sendo, com esta tese de Doutoramento, Maria Amélia Campos presta reais contributos pela novidade metodológica, multidisciplinar. Este estudo trouxe, ainda, numa escala mais ampla, novas luzes à História Urbana da Coimbra medieva, cujo conhecimento será tanto maior quanto a multiplicação de estudos idênticos às paróquias limítrofes, permitindo assim do particular chegar a um todo que urge 
conhecer mais e melhor. Por fim, cremos poder-se dizer que Santa Justa de Coimbra já não é mais uma instituição/entidade/estrutura que se esconde na Idade Média. O estudo encetado por Maria Amélia Campos trouxe a colegiada e a paróquia até aos dias de hoje, qual pelicano renascido das cinzas... Que venham mais!

\section{COMO CITAR ESTE ARTIGO}

\section{Referência electrónica:}

BOTELHO, Maria Leonor - "CAMPOS, Maria Amélia Álvaro de - Santa Justa de Coimbra na Idade Média: o espaço urbano, religioso e socio-económico. Coimbra: 2012. Disseração de Doutoramento em História da Idade Média, apresentada à Faculdade de Letras da Universidade de Coimbra, sob orientação da Professora Doutora Maria Helena da Cruz Coelho, 2 volumes (texto policopiado)". Medievalista [Em linha]. Nº14, (Julho - Dezembro 2013). [Consultado dd.mm.aaaa]. Disponível em http://www2.fcsh.unl.pt/iem/medievalista/MEDIEVALISTA14/botelho1409.html.

ISSN 1646-740X.

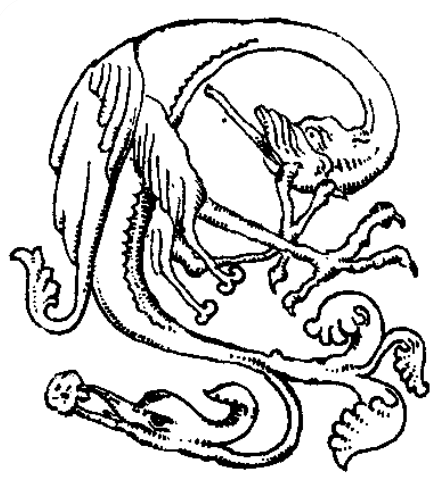

